\title{
GENETICS AND EVOLUTION
}

UNDERSTANDING EVOLUTION. E. Peter Volpe. Wm. C. Brown Company, lowa. Pp. xvi and 160 (Paperback), \$2.25.

The preface of this book states that it is intended " to provide a simple, concise account of the scope and significance of evolution for the college student seeking a liberal education". It begins this task by discussing the distinction between heritable and non-heritable variation. The facts of environmental modification leads to a consideration of the views of Lamarck and Lysenko and thence to Darwin and natural selection.

The second chapter is concerned with the origin of genetic variation and is a brief outline of Mendelian genetics and of the particular importance of mutation and recombination (not neglecting to describe the structure of DNA) in providing the variation on which natural selection can act. The next five chapters provide an elementary but lucid account of population genetics leading up to balanced polymorphisms and random genetic drift. Only one possible mechanism, heterozygote advantage, for the maintenance of a balanced polymorphism is mentioned and, for this reviewer's taste, too much emphasis is placed on the role of drift. But the most serious omissions are of any discussion of the importance of continuously varying characters in the evolution of populations and of a consideration of the concepts of co-adaptation and balanced genotypes and population structure. These omissions make the transition from the section on population genetics to that on the evolution of races and species unnecessarily sudden.

The latter half of the book is concerned with the evolution of separate populations, discussing isolating mechanisms, cataclysmic evolution (changes in ploidy level), adaptive radiation and convergent evolution. It ends with speculative chapters on the origin of life and of man.

Despite its faults this readable and attractively laid out book provides a good introduction to the genetic study of evolution and could be recommended for sixth-form teaching, particularly in the teaching of biology as an "elective" subject if currently suggested reforms for A-level work are accepted.

\author{
K. J. R. EDWARDs \\ Department of Genetics, University of Cambridge
}

\section{THE SUB-DIVISIONS OF HOMO SAPIENS}

THE LIVING RACES OF MAN. Carleton S. Coon. Jonathan Cape. London. 1966. 70 s.

Dr Carleton Coon, at one time best known as the author of a definitive pre-war monograph on The Races of Europe, has, during the past four years, attained a further peak of anthropological prominence mainly as a result of criticism, at times reasoned, at others carping, directed towards a monograph, setting out his views on The Origin of Races. Here, Dr Coon developed the concept that the major geographical groups of extant man had evolved independently and in parallel for a much longer period than is often believed to be the case. As a result, they should, he submitted, properly be regarded as zoological subspecies.

In this earlier monograph, based on an all too limited fossil record, it was further argued that some major geographical subgroups had developed for longer peroids than others - an assertion that led to unfortunate implications 
about differences in the degree of evolutionary development. Fear of the possibility of emphasis and distortion, out of context, of such parts of the book, was a factor that initiated much of the professional criticism of Dr Coon's earlier volume.

The present work deals in detail with differences between major and minor subdivisions of living man, and represents an attempt to include the panorama of modern knowledge of comparative morphology, biometrics, physiology and genetics. It has been written, with a clear consciousness of the unfortunate racialist implications attributed to the thesis developed in the earlier monograph, and it is not surprising that Dr Coon's introductory paragraphs should include a plea "... that no one shall quote or cite this book as ammunition for or against any cause or movement whatsoever . ..". And it must be said, in fairness, that each chapter shows obvious signs that Dr Coon and his collaborators have taken much care to ensure that the text is framed to avoid misrepresentation of the type that attended his earlier publication.

The initial chapter reiterates the zoological concept of race as a subdivision of a species, and recapitulates the five-fold geographical division of extant Homo sapiens. This separation was, presumably, reasonably clear before the rapid development of means of communication and consequent population movement of the last four centuries. But now, it is in some areas obscured, in others complicated, as a result of such interchange. The text continues with synoptic accounts of the various methods, in the past used independently, but in modern times, in combination, to provide a basis for classification, and there is brief mention of the contributions made to racial classification from the fields of gross morphology, biometrics, comparative physiology and genetics.

A further chapter discusses the isolating mechanisms that have been operative in human populations. Geographical separation, even though influenced by developments in transportation, has appropriate prominence, although cultural, linguistic and related factors, specific to human populations, also receive suitable mention.

The following five chapters deal with each of the major geographical human variants in turn (Caucasoid, Congoid, Capoid, Mongoloid, Australoid), and with their several subdivisions. The descriptions, presented in the author's typical flowing style, are to no small extent based upon studies of comparative morphology. But in each instance, the secular development of each group from pre-historic times, is treated at some length, while linguistic similarities and differences are used as additional " markers".

This survey, comprising a panorama of accumulated knowledge and experience, could well prove to be a climax of the classical approach to the definition of the major geographical human groups and their subdivisions.

It is in the next two chapters that Dr Coon incorporates the taxonomic concepts that have effectively pervaded and enhanced the field of zoological classification during the last twenty-five years. Again, extensive synopses are provided of morphological and physiological features that can be established as of adaptive (selective) significance. There is also some account of the body of information dealing with the distribution of certain major genetic factors-notably the blood groups-and of how selective pressure acting either directly or upon features correlated with these, has resulted in polymorphisms, now well defined in many parts of the world. 
It is, at this point, that the critical reader becomes, by implication, aware of the problems, many shared with the taxonomy of other mammalian groups, but an even greater number unique to man, that beset attempts to effect a true biological classification of Homo sapiens.

Even if it is possible to assess and make allowance for the effects of the movement of populations since the Middle Ages, and especially during the nineteenth and twentieth centuries, many difficulties remain. What, in fact, are the true effects, as isolating mechanisms, of culture and language as compared with, for instance, geographical barriers? What relative significance should be attached to morphological features such as overall bodily proportions whose genetic basis although undefined, is almost certainly multifactorial, as compared with others controlled by small numbers of major, and therefore readily identifiable genetic factors? Again, is it appropriate to give different weights to characters that have a clear adaptive (selective) significance, as opposed to others, to which no such meaning can yet be readily attributed?

Problems of this type can, profitably, be argued at length, and some readers will regret that $\mathrm{Dr}$ Coon has not included, in his monograph, a critical synopsis of current thought in this sphere. Should, for instance, the whole problem be regarded as a giant exercise in multivariate analysis; or could such a study do little more than point to the huge gaps in data that still have to be filled? Alternatively, are the unique selective and counter selective forces now operating upon human populations as a result of man's cultural and technological development likely to introduce such a completely new dimension into his future evolution that the study of human subgroups can no longer be carried out profitably on the basis of techniques appropriate to other mammalian groups?

Discussion of such matters must surely be more positive than speculation about the possible future course of man's physical evolution. But even the most severe critic of Dr Coon's work could scarcely wish to limit the expression, in the closing pages of his book, of his personal hope that as human development proceeds, ". . . all members of all races and cultures can be given congenial and interesting work to do, or else be allowed to live undisturbed according to their own traditional cultural patterns as long as they like".

E. H. Ashton

Department of Anatomy, The Medical School, Birmingham University, Birmingham 15

\section{GEOGRAPHICALLY-LIMITED POPULATIONS}

FAMILIAL INTERRELATEDNESS IN A SWEDISH RURAL POPULATION. E. Essen-Möller. S. Karger, Basel: Supplementum ad Acta Genetica et Statistica Medica, Volume 17, 1967. Pp. 77 .

There can be no doubt that a complete knowledge of the structure of a population, be it human or animal, is of the utmost interest to the geneticist. So much of the theory of gene dynamics, and hence ultimately of evolution, rests upon idealised population structures (or no structure at all, as with the "infinite random-mating population"), that it is vital to elucidate real structures and investigate their properties.

Paradoxically, the advent of the computer has provided a tool which at one and the same time enables population data to be tabulated and analysed in a huge variety of ways, and renders obsolete most of these 